\title{
Análise morfométrica da Microbacia do riacho Riachão, no Parque Nacional de Sete Cidades, Nordeste do Brasil
}

\author{
Morphometric analysis of the Watershed Riachão Stream in Sete Cidades National Park, \\ Northeast Brazil
}

MENDES $^{1}$, J. M.; PACIÊNCIA ${ }^{2}$, L. G. M.; SANTOS $^{3}$, F.A.; AQUINO ${ }^{4}$, C. M. S. jhullimmendes@gmail.com

\begin{abstract}
Resumo
O presente artigo teve como objetivo realizar a análise dos parâmetros morfométricos da Microbacia do riacho Riachão (MRR), no interior do Parque Nacional de Sete Cidades, localizado no estado do Piauí. O conhecimento de tais parâmetros é de grande importância para preservar os recursos naturais das Unidades de Conservação (UC). A delimitação da MRR foi realizada através do Sistema de Informações Geográficas (SIG) ArcGIS 10. Os resultados obtidos possibilitaram constatar que a microbacia apresenta hierarquia fluvial de terceira ordem e formato circular, com canais pouco ramificados que permitem menor escoamento superficial. A caracterização dos parâmetros geométricos, da rede de drenagem e do relevo permitiu inferir que a microbacia está sujeita a enchentes, em consequência de seu baixo coeficiente de compacidade $(\mathrm{Kc})$. A densidade hidrográfica também apresenta um valor baixo, diminuindo a capacidade de geração de novos cursos d'água.
\end{abstract}

Palavras-chave: Unidade de Conservação. Parâmetros Geométricos. Recurso hídrico.

\begin{abstract}
This article aimed to conduct an analysis of morphometric parameters of the Watershed Riachão Stream (WRS), inside the Sete Cidades National Park, located in the state of Piauí. The knowledge of these parameters is of great importance for the realization of environmental actions to conserve natural resources of Conservation Units. In this context, the WRS's delimitation was performed using the Geographic Information System (GIS) ArcGIS 10, starting the analysis by the drainage network. With the results was possible to note that the watershed has fluvial hierarchy of third order and circular format, with little branched channels that allow less water runoff. The characterization of geometric parameters, drainage network and topography allows to infer that the watershed is subject to flooding, as a result of its low compactness coefficient $(\mathrm{Kc})$. The hydrographic density also has a low value, reducing the capacity to generate new watercourses.
\end{abstract}

Keywords: Conservation Unit. Geometrical Parameters. Water Resource.

\section{INTRODUÇÃO}

O conceito de bacia hidrográfica é definido por Novo (2008) como a área da superfície terrestre drenada por um rio principal e seus tributários, correspondendo a uma área de captação natural da água da precipitação cujo escoamento converge para um único ponto de saída, chamado exutório.

$\mathrm{O}$ estudo de tais áreas fornece dados e informações, que servem de referência para o planejamento ambiental e a avaliação de índices importantes para a prevenção de riscos ambientais, a exemplo dos parâmetros geométricos, além dos limites da Área $(A)$ e Perímetro $(P)$, utilizou-se o Fator Forma de Bacia $(F f)$, definido como a razão entre a largura média da bacia e o comprimento do eixo da bacia, o Índice de Circularidade (Ic) e o Coeficiente de Compacidade $(K c)$, que diz respeito à relação entre o perímetro da bacia e o perímetro de um círculo de mesma área que a bacia (CARVALHO e SILVA, 2006). 
Por sua vez, para caracterização da rede de drenagem consideraram-se: o comprimento total dos cursos d'água ( $L$ total); a Densidade de Drenagem $(D d)$ expressa pela relação entre o comprimento total dos cursos d'água ( $L$ total) de uma bacia e sua área; a Densidade hidrográfica $(D h)$ que expressa o número de canais existentes em cada quilômetro (MIRANDA et al., 2011); a partir da $D d$ é possível obter-se o Coeficiente de manutenção $(\mathrm{Cm})$, que corresponde à área mínima necessária para a manutenção de um metro de canal de escoamento (TONELLO et. al., 2006); e a ordem dos cursos d'água que representa o grau de ramificação do sistema de drenagem da bacia, obtido conforme proposta de Strahler (1952).

Quanto às características do relevo abordaram-se: a altitude mínima $\left(H_{\min }\right)$; altitude máxima $\left(H_{\max }\right)$; a altitude média, média da soma da altitude mínima $\left(H_{\min }\right)$ com a altitude máxima $\left(H_{\max }\right)$; amplitude altimétrica máxima da Microbacia amplitude $\left(H_{t}\right)$, obtida a partir da subtração da altitude máxima e altitude mínima; e Índice de rugosidade (Ir), encontrado a partir do produto amplitude altimétrica pela densidade de drenagem (SOARES e SOUZA, 2012).

Para analisar as características do relevo, levaram-se em conta os valores da altitude, bem como da declividade, que é expressa como a variação de altitude entre dois pontos do terreno, em relação à distância que os separa. Outro parâmetro importante é o Índice de Rugosidade, produto da amplitude altimétrica e da densidade de drenagem (SOARES e SOUSA, 2012).

Martins (2012) afirma que toda bacia hidrográfica é composta por uma rede de drenagem constituída por rios, riachos, córregos e pântanos ou várzeas, que naturalmente se formaram e se mantém em função da dinâmica das precipitações e das características do terreno. Os autores empregaram o modelo de rede de drenagem criado por Horton (1945) e modificado por Strahler (1952). O modelo mostra a classificação fluvial dos rios, levando em conta o grau de movimentação e o percurso feito pelas águas até sua chegada à foz (CHRISTOFOLETTI, 1980).

Alves Sobrinho et al. (2010) delimitaram bacia hidrográfica na Área de Proteção Ambiental (APA) do Guariroba através de dados do projeto Shuttle Radar Topographic Mission (SRTM). O estudo constatou que a delimitação automática pelo SRTM apresenta vantagem em relação ao custo e benefício proporcionado, com precisão compatível à metodologia baseada em cartas topográficas.

Soares e Souza (2012) realizaram uma análise dos parâmetros morfométricos do relevo e da rede de drenagem da bacia do Rio Pequeno, no Paraná. O cálculo dos índices e parâmetros foi realizado a partir de imagens de satélite, cartas topográficas e programas especializados, permitindo constatar que a bacia possui controle lito-estrutural, forma alongada e alta densidade de drenagem. $\mathrm{O}$ estudo possibilitou uma melhor compreensão da vulnerabilidade natural à erosão da bacia estudada.

A partir de dados do SRTM e realizando o método de interpolação pelo software MAPINFO, Miranda et al. (2011) analisaram dados morfométricos para o levantamento das características 
físicas da microbacia do córrego dos Bois, no Parque Estadual da Lapa Grande. O estudo possibilitou evidenciar que os terrenos da microbacia apresentam um baixo grau de infiltração, com relevo montanhoso no curso médio da bacia, além de ser alongada e possibilitar um maior escoamento superficial com uma menor tendência a enchentes.

Tomando-se por base os trabalhos acima mencionados, o presente estudo propôs-se a realizar uma análise dos parâmetros morfométricos do relevo e da rede de drenagem da Microbacia do riacho Riachão (MRR), situado no interior do Parque Nacional de Sete Cidades, Nordeste do estado do Piauí, visando ações de conservação ambiental.

\section{METODOLOGIA}

\subsection{Localização e caracterização geográfica da área em estudo}

O PARNA de Sete Cidades foi criado através do Decreto Federal no 50.744, de 08 de junho de 1961 (BRASIL, 1961). O mesmo situa-se no Nordeste do Estado do Piauí, especificamente entre os municípios de Brasileira e Piracuruca. A referida Unidade de Conservação (UC) possui 6.221 ha de extensão (BRASIL, 1979). Nesse contexto insere-se a Microbacia do riacho Riachão (MRR), conforme apresentado na Figura 01. 


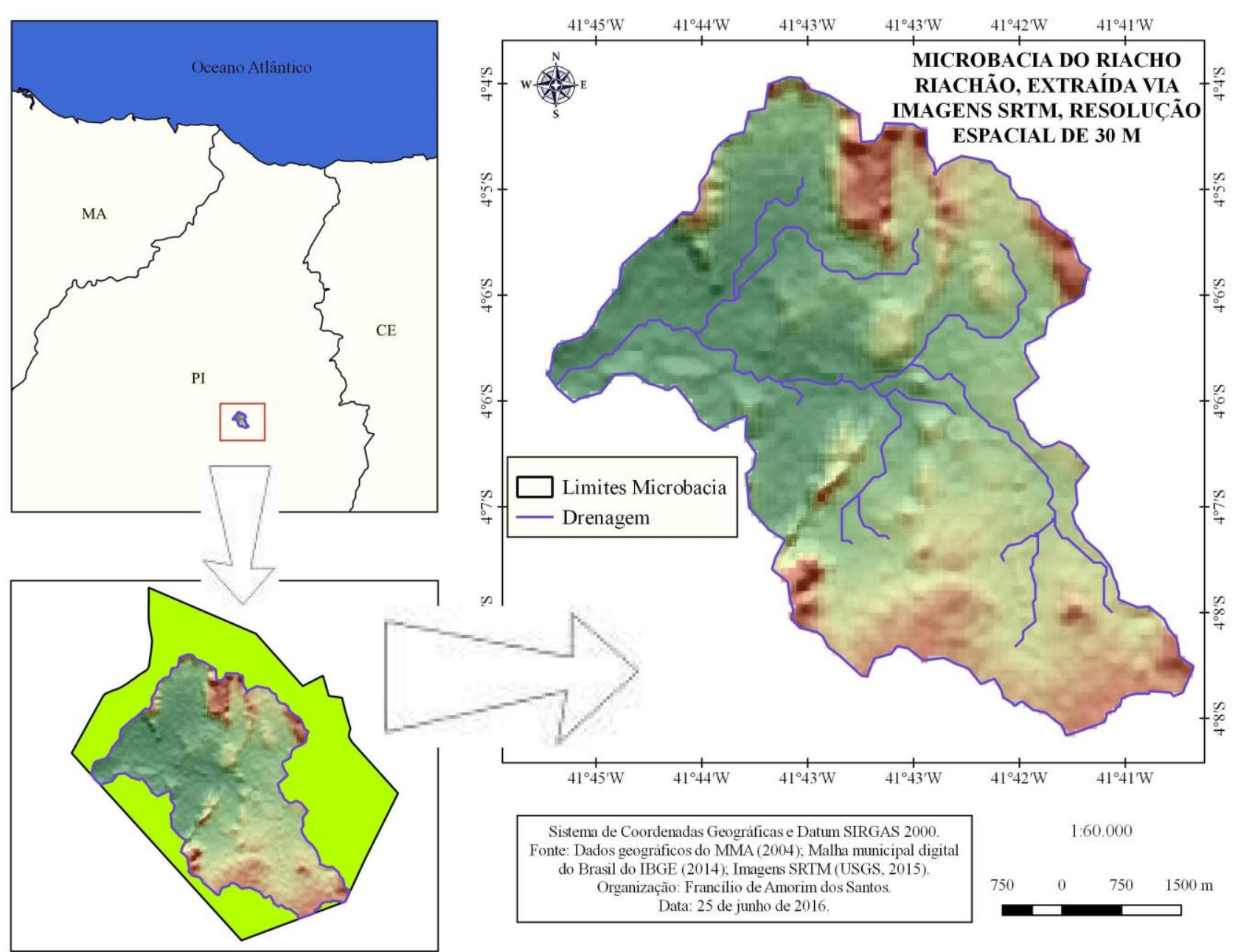

Figura 01. Localização do riacho Riachão (MRR) no interior do Parque Nacional de Sete Cidades, obtido através da extração de bacias via SRTM (USGS, 2015), dados geográficos do MMA (2004) e malha municipal digital do Brasil (IBGE, 2014).

\subsection{Procedimentos e técnicas}

Para delimitação da Microbacia do riacho Riachão (MRR) utilizou-se a técnica de delimitação automática de bacias hidrográficas. As feições de drenagem e divisores de água são convertidas em vetores, como aponta (ALVES SOBRINHO, 2010; SILVA e MOURA, 2013).

A delimitação automática da MRR foi realizada através do Sistema de Informação Geográfica (SIG) ArcGIS 10, cuja licença foi adquirida pelo Laboratório de Geomática vinculado à Universidade Federal do Piauí. Utilizou-se para extração automática o Modelo Digital de Elevação (MDE), folha SB-24-V-A, da missão Shuttle Radar Topography Mission (SRTM), com resolução espacial de 30 metros, adquirida junto ao site <http://earthexplorer.usgs.gov/>, do Serviço Geológico dos Estados Unidos (USGS).

A metodologia utilizada constou de etapas realizadas, conforme Figura 02, nos Menus Spatial Analyst e Ferrramenta Hydrology (etapas 1 a 5), Conversion e ferramenta Raster To Polygon (etapa 6), Analyst e ferramenta Extract (etapa 7) (Figura 02): 
Etapa 1: fill (preencher) para preenchimento de pequenas imperfeições nos dados MDE SRTM;

Etapa 2: flow direction (direção de fluxo) que gerou o arquivo de direção do fluxo;

Etapa 3: flow accumulation (acumulação de fluxo) para determinar a acumulação do fluxo a partir do flow direction, criado na etapa anterior;

Etapa 4: basin (bacia hidrográfica) para delimitação das bacias hidrográficas via SRTM;

Etapa 5: con (conditional) utilizada para gerar a rede de drenagem, considerando valores superiores a 1.000;

Etapa 6: raster to polygon (raster para polígono) e raster to polyline (raster para linha) para conversão dos arquivos raster para vetorial (polígono e linha);

Etapa 7: clip (cortar) utilizada para selecionar as feições de interesse para o estudo, limites da MRR e a rede de drenagem.

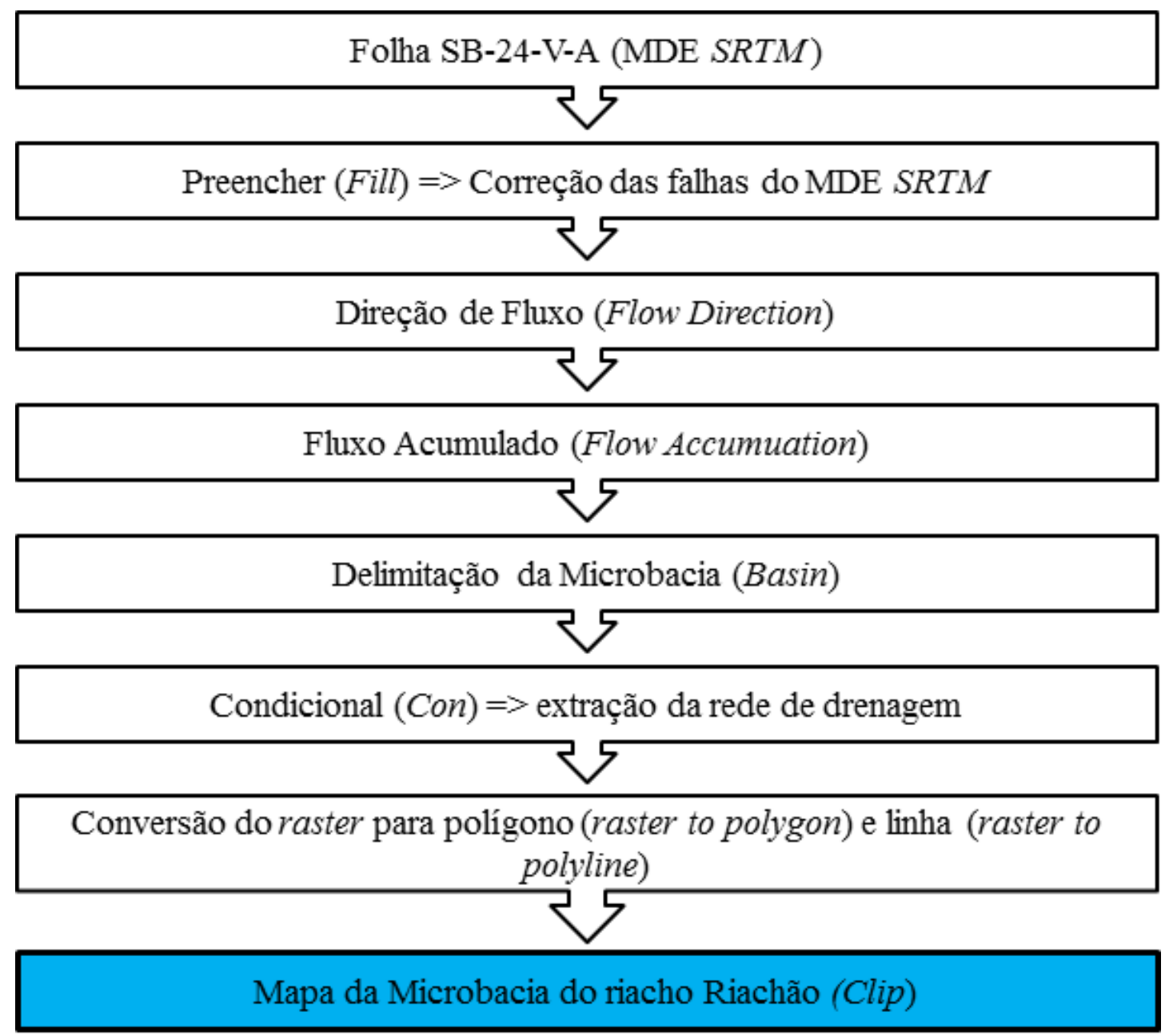

Figura 02. Etapas realizadas para delimitação da Microbacia do riacho Riachão (MRR) a partir do MDE SRTM.

A análise morfométrica inicia-se pela rede de drenagem, considerando-se inicialmente a ordenação de seus canais fluviais, para fins de estabelecimento da hierarquia fluvial. Nesse sentido, adotou-se a classificação dos rios proposta por Horton (1945) e posteriormente modificada por 
Strahler (1952). Esta elimina o conceito do primeiro de que o rio principal deva ter o mesmo número de ordem em toda sua extensão, necessitando-se refazer a numeração dos rios a cada confluência (CHRISTOFOLETTI, 1980), conforme é apresentado na Figura 03.

Diante do exposto, procedeu-se a análise das variáveis morfométricas conforme definições apresentadas no Quadro 01.
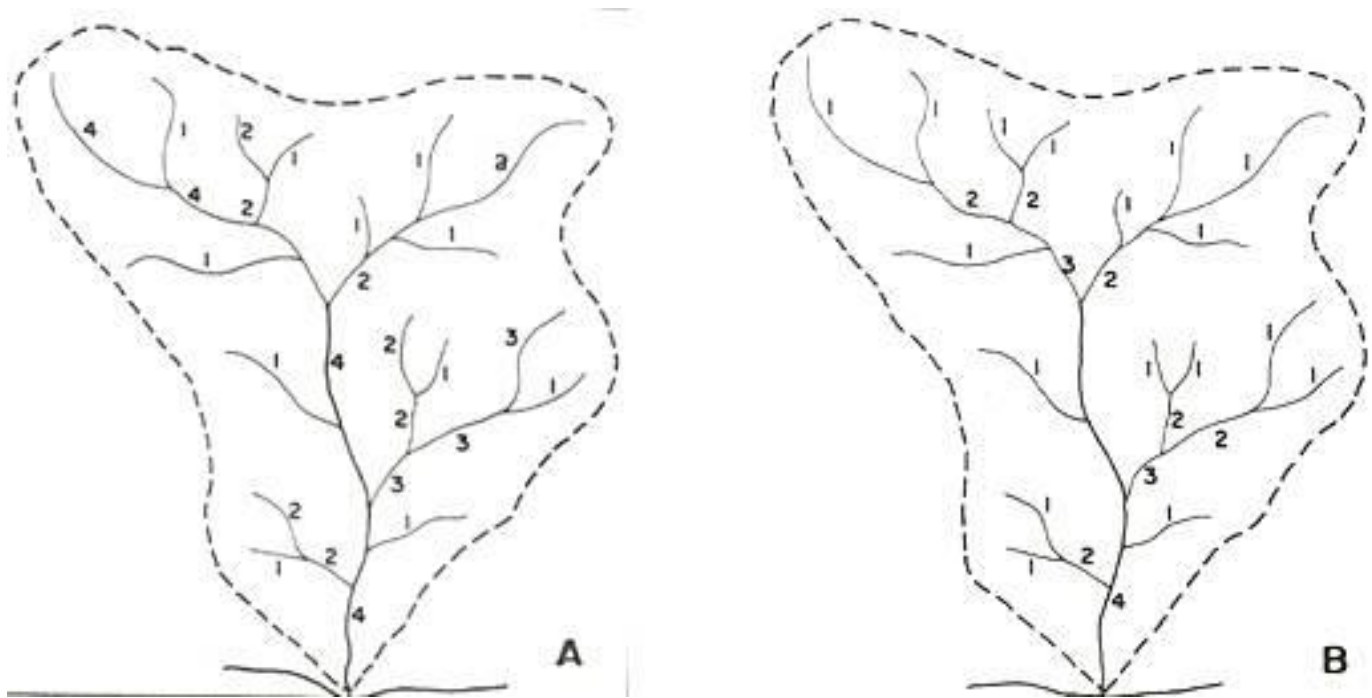

Figura 03. Modelos para determinação da ordem e hierarquia das bacias hidrográficas, de acordo com Horton (desenho A) e Strahler (desenho B).

Quadro 01. Características morfométricas analisadas da Microbacia do riacho Riachão (MRR).

\begin{tabular}{|c|c|c|c|c|}
\hline Característica & Parâmetro & Equação & Definição & Unidade \\
\hline \multirow{5}{*}{ Geométrica } & Área $(A)$ & $A$ & $A=$ área da bacia em $\mathrm{km}^{2}$. & $\mathrm{km}^{2}$ \\
\hline & Perímetro $(P)$ & $P$ & $P=$ perímetro da bacia em $\mathrm{km}^{2}$. & $\mathrm{km}^{2}$ \\
\hline & $\begin{array}{l}\text { Fator forma da } \\
\text { bacia }(F f)\end{array}$ & $F f=\frac{A}{L^{2}}$ & $\begin{array}{c}A=\text { área da bacia em } \mathrm{km}^{2} ; \\
L=\text { comprimento do eixo }(\mathrm{km}) .\end{array}$ & - \\
\hline & $\begin{array}{c}\text { Índice de } \\
\text { circularidade (Ic) }\end{array}$ & $I c=\frac{M c}{M l}$ & $\begin{array}{c}M c=\text { maior comprimento } \\
M l=\text { maior largura }\end{array}$ & - \\
\hline & $\begin{array}{c}\text { Coeficiente de } \\
\text { compacidade }(K c)\end{array}$ & $K c=\frac{0.28 P}{\sqrt{A}}$ & $\begin{array}{c}A=\text { área da bacia em } \mathrm{km}^{2} ; \\
P=\text { perímetro da bacia em } \mathrm{km}^{2} .\end{array}$ & - \\
\hline \multirow{5}{*}{$\begin{array}{l}\text { Rede de } \\
\text { drenagem }\end{array}$} & $\begin{array}{l}\text { Comprimento total } \\
\text { dos cursos d'água } \\
(L \text { total })\end{array}$ & $L$ & $\begin{array}{c}L=\text { comprimento total dos cursos } \\
\text { d'água }(\text { L total em } \mathrm{km})\end{array}$ & $\mathrm{km}$ \\
\hline & $\begin{array}{l}\text { Densidade de } \\
\text { drenagem }(D d)\end{array}$ & $D d=\frac{L t}{A}$ & $\begin{array}{c}L t=\text { comprimento total dos } \\
\text { canais em } \mathrm{km} ; A=\text { área da bacia } \\
\mathrm{em} \mathrm{km}^{2} .\end{array}$ & $\mathrm{km} / \mathrm{km}^{2}$ \\
\hline & $\begin{array}{l}\text { Densidade } \\
\text { hidrográfica }\end{array}$ & $D h=\frac{n}{A}$ & $\begin{array}{c}n=\text { número de canais; } A=\text { área } \\
\text { total da bacia em } \mathrm{km}^{2} .\end{array}$ & canais $/ \mathrm{km}^{2}$ \\
\hline & $\begin{array}{c}\text { Coeficiente de } \\
\text { manutenção }(\mathrm{Cm})\end{array}$ & $C m=\frac{1}{D d} \times 1000$ & $\begin{array}{c}D d=\text { densidade de drenagem em } \\
\mathrm{km} / \mathrm{km}^{2} .\end{array}$ & $\mathrm{m}^{2} / \mathrm{m}^{-1}$ \\
\hline & $\begin{array}{l}\text { Ordem dos cursos } \\
\text { d'água }\end{array}$ & - & - & - \\
\hline \multirow[b]{4}{*}{ Relevo } & Altitude mínima & $H_{\min }$ & $H_{\min }=$ altitude mínima & M \\
\hline & Altitude máxima & $H_{\max }$ & $H_{\max }=$ altitude máxima & $\mathrm{M}$ \\
\hline & Altitude média & $\frac{H_{\min }+H_{\min }}{2}$ & $\begin{array}{l}H_{\min }=\text { altitude mínima } \\
H_{\max }=\text { altitude máxima }\end{array}$ & M \\
\hline & Amplitude & $H_{t}$ & & \\
\hline
\end{tabular}




\begin{tabular}{|c|c|c|c|c|}
\hline & $\begin{array}{c}\text { altimétrica máxima } \\
\text { da Microbacia }\end{array}$ & & $H_{t}=$ amplitude altimétrica em $\mathrm{m}$ & $\mathrm{m}$ \\
\cline { 2 - 5 } & $\begin{array}{l}\text { Índice de } \\
\text { rugosidade }(\text { Ir })\end{array}$ & $\operatorname{Ir}=H \times \mathrm{Dd}$ & $\begin{array}{c}H=\text { amplitude altimétrica em } \mathrm{m} ; \\
\text { Dd } ;=\text { densidade de drenagem em } \\
\mathrm{km} / \mathrm{km}^{2} .\end{array}$ & - \\
\hline
\end{tabular}

\section{RESULTADOS E DISCUSSÃO}

A classificação proposta por Strahler (1952) considera que os canais de primeira ordem são aqueles que não apresentam tributários, sendo canais de cabeceiras de drenagem. Já os canais de segunda ordem são subsequentes à confluência de dois canais de primeira ordem e assim sucessivamente. A técnica aplicada ao estudo possibilitou identificar que a MRR é uma microbacia de terceira ordem, apresentando área total de $32,4 \mathrm{~km}^{2}$ e perímetro de $30,9 \mathrm{~km}^{2}$. A Figura 04 apresenta a hierarquia fluvial do riacho Riachão.

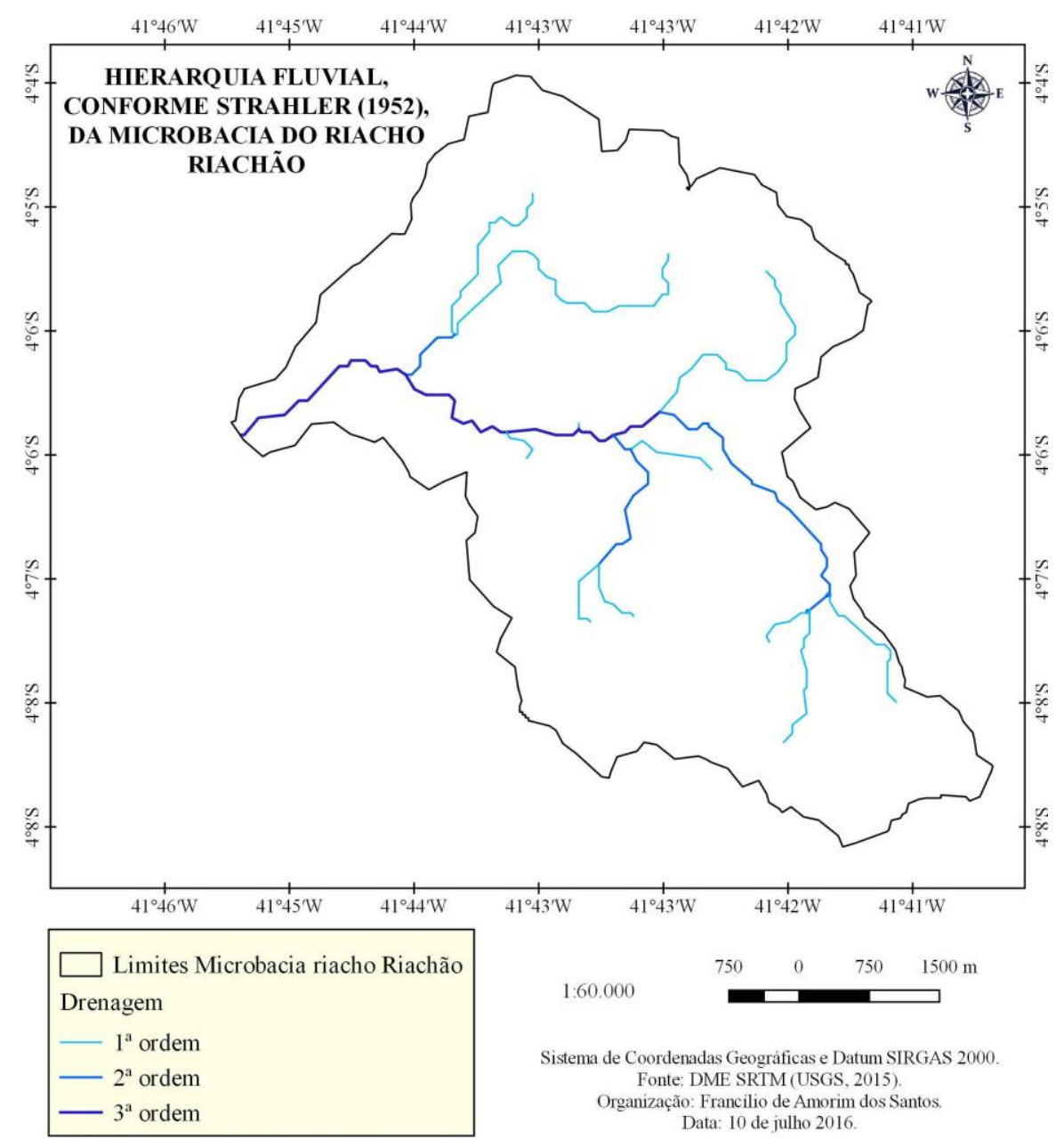

Figura 04. Hierarquia Fluvial, conforme proposta de Strahler (1952), da Microbacia do riacho Riachão. 
A Tabela 01 possibilita observar que a microbacia estudada possui 14 canais de primeira ordem, 3 canais de segunda ordem e seu canal principal de terceira ordem. A maioria de seus segmentos é de primeira ordem, estes representam $77,8 \%$ do comprimento total do riacho, o que possibilita inferir que a MRR apresenta um sistema de drenagem com poucas ramificações e, consequentemente, pouco eficiente, possivelmente também resultado da pequena área da bacia.

Tabela 01. Composição da rede de drenagem da Microbacia do riacho Riachão. Fonte: Organizada pelos autores (2016).

\begin{tabular}{c|c|c|c|c}
\hline $\begin{array}{c}\text { Ordem dos } \\
\text { canais }\end{array}$ & $\begin{array}{c}\mathbf{N}^{\mathbf{0}} \text { de } \\
\text { segmentos }\end{array}$ & $\begin{array}{c}\text { Comprimento dos } \\
\text { Canais }(\mathbf{k m})\end{array}$ & $\begin{array}{c}\text { Comprimento Médio } \\
\text { dos Canais (km) }\end{array}$ & $\begin{array}{c}\% \\
\text { Segmentos }\end{array}$ \\
\hline $1^{\mathrm{a}}$ & 14 & 0,14 & 0,01 & 77,8 \\
\hline $2^{\mathrm{a}}$ & 3 & 0,05 & 0,02 & 16,7 \\
\hline $3^{\mathrm{a}}$ & 1 & 0,05 & 0,05 & 5,5 \\
\hline Total & $\mathbf{1 8}$ & $\mathbf{0 , 2 4}$ & - & $\mathbf{1 0 0}$ \\
\hline
\end{tabular}

O Quadro 02 apresenta as variáveis morfométricas analisadas no presente estudo. Desse modo, foi possível identificar que o fator forma de bacia $(F f)$ apresenta valor mediano, enquanto o Índice de circularidade (Ic) de 1,34 indica que a MRR tende a ser mais circular, favorecendo os processos de inundação. Por apresentar um Coeficiente de compacidade $(K c)$ menor que 1 , seu formato é mais arredondado e pode haver ocorrência de enchentes.

Ainda de acordo com o Quadro 02, a Microbacia estudada apresenta um índice muito baixo de densidade de drenagem $(D d)$, pois de acordo com Benatti et al. (2015), esse a $D d$ tem relação com a litologia, pois em áreas onde a infiltração é dificultada ocorrerá maior escoamento superficial e como consequência, baixo abastecimento do lençol freático. A MRR possui baixa capacidade de gerar novos cursos d'água, em decorrência de sua baixa densidade hidrográfica.

Quadro 02. Características morfométricas analisadas da Microbacia do riacho Riachão (MRR).

\begin{tabular}{|c|c|c|}
\hline Característica & Parâmetro & Unidade \\
\hline \multirow{4}{*}{ Geométrica } & Área (A) & $32,4 \mathrm{~km}^{2}$ \\
\cline { 2 - 3 } & Perímetro (P) & $30,9 \mathrm{~km}^{2}$ \\
\cline { 2 - 3 } & Fator forma da bacia (Ff) & 0,48 \\
\cline { 2 - 3 } & Índice de circularidade (Ic) & 1,34 \\
\cline { 2 - 3 } & Coeficiente de compacidade (Kc) & 0,40 \\
\hline \multirow{4}{*}{$\begin{array}{c}\text { Rede de } \\
\text { drenagem }\end{array}$} & Comprimento total dos cursos d'água (L total) & $0,24 \mathrm{~km}$ \\
\cline { 2 - 3 } & Densidade de drenagem (Dd) & $0,1 \mathrm{~km} / \mathrm{km}^{2}$ \\
\cline { 2 - 3 } & Densidade hidrográfica & $0,55 \mathrm{canais} / \mathrm{km}^{2}$ \\
\cline { 2 - 3 } & Coeficiente de manutenção (Cm) & $10.000 \mathrm{~m}^{2} / \mathrm{m}^{-1}$ \\
\cline { 2 - 3 } & Ordem dos cursos d'água & $173 \mathrm{~m}$ \\
\hline \multirow{4}{*}{ Relevo } & Altitude mínima & $241 \mathrm{~m}$ \\
\cline { 2 - 3 } & Altitude máxima & $207 \mathrm{~m}$ \\
\cline { 2 - 3 } & Altitude média & $68 \mathrm{~m}$ \\
\cline { 2 - 3 } & Amplitude altimétrica máxima da Microbacia & 680 \\
\cline { 2 - 3 } & Índice de rugosidade (Ir) & \\
\cline { 2 - 3 } & & \\
\hline
\end{tabular}


Os dados do Quadro 02, acima, possibilitam afirmar que o Coeficiente de manutenção $(\mathrm{Cm})$ da MRR demanda $10.000 \mathrm{~m}^{2}$ de área para manter perene cada metro de seus canais. Representando aspectos da declividade, o alto índice de rugosidade (Ir) da área implica relevo colinoso e dissecado em determinadas regiões, variando de acordo com a densidade de drenagem.

\section{CONSIDERAÇÕES FINAIS}

O presente trabalho possibilitou realizar a análise dos parâmetros morfométricos da Microbacia do riacho Riachão (MRR), no interior do Parque Nacional de Sete Cidades. Foi possível identificar que a MRR, de acordo coma a classificação de Strahler (1952), é classificada como de $3^{\mathrm{a}}$ ordem, sendo que $77,8 \%$ de sua área é drenada por canais de $1^{\text {a }}$ ordem.

No que diz respeito às variáveis geométricas a MRR apresentou fator forma de bacia (Ff) mediana, ao passo que seu Índice de circularidade (Ic) é de 1,34, indicando uma tendência mais circular, e seu Coeficiente de compacidade $(K c)$ menor que 1, representando um formato mais arredondado, favorecem processos de inundação.

As características da rede de drenagem apontaram muito baixa Densidade de drenagem $(D d)$, resultando em menor capacidade de infiltração e maior escoamento superficial. A MRR apresenta, ainda, baixa capacidade de gerar novos cursos d'água, devido sua baixa densidade hidrográfica. Por sua vez, o Coeficiente de manutenção $(\mathrm{Cm})$ da Microbacia demanda $10.000 \mathrm{~m}^{2}$ de área para perenização de cada metro de seus canais.

Por sua vez, o relevo apresenta altitude média de 207 metros e seu alto Índice de rugosidade (Ir), que implica relevo colinoso e dissecado em determinadas áreas, que varia de acordo com sua Densidade de drenagem.

A metodologia aplicada mostrou-se eficaz ao atender os objetivos previamente estabelecidos. Recomenda-se a aplicação para as demais bacias, sub-bacias e microbacias hidrográficas do estado do Piauí, como forma de ampliar os conhecimentos e promover a conservação dos recursos hídricos superficiais do Estado.

\section{REFERÊNCIAS}

ALVES SOBRINHO, T. Delimitação automática de bacias hidrográficas utilizando dados SRTM. Engenharia Agrícola, Jaboticabal, v.30, n.1, p.46-57, jan./fev. 2010.

BENATTI, D.P.; TONELLO, K.C.; LEITE, E.C.; FARIA, LC. Morfometria e uso e cobertura de uma Microbacia no município de Sete Barras, São Paulo. Irriga, Botucatu, v. 20, n. 1, p. 21-32, janeiro-março, 2015. 
BRASIL. Decreto $\mathbf{n}^{\mathbf{0}}$ 50.744, de 8 de junho de 1961. Cria o Parque Nacional de Sete Cidades, integrante da Seção de Parques e Florestas Nacionais do Serviço Florestal, do Ministério da Agricultura.

BRASIL. Ministério da Agricultura. IBDF - Instituto Brasileiro de Desenvolvimento Florestal. Fundação Brasileira para a Conservação da Natureza. Plano de Manejo do Parque Nacional de Sete Cidades. Documento Técnico, n. 1. Brasília, 1979.

CARVALHO, D.F.; SILVA, L.D.B. Bacia Hidrográfica. In: Hidrologia, 2006. p. 15-32.

CHRISTOFOLETTI, A. Geomorfologia. 2.ed. rev. e ampl. São Paulo: Edgard Blücher, 1980.

HORTON, R.E. Erosional development of streams and their drainage basins: hydrophysical approach to quantitative morphology, Geol. Soc. America Bulletin, 1945, 56 (3), p.275-370.

IBGE - Instituto Brasileiro de Geografia e Estatística. Malha municipal digital do Brasil: situação em 2010. Rio de Janeiro: IBGE, 2012. Disponível em: <ftp://geoftp.ibge.gov.br/malhas_digitais/>. Acesso em 27 de agosto de 2015.

MARTINS, J.R.S. Gestão de drenagem urbana: só tecnologia será suficiente?. Artigo científico, Universidade de São Paulo, julho de 2012, p.1-11.

MIRANDA, W.A.; MELO, A.A.M.; FIGUEIREDO, F.P.; OLIVEIRA, F.G. A importância do uso do SIG e da análise morfométrica para o plano de manejo em unidades de conservação. Anais XV Simpósio Brasileiro de Sensoriamento Remoto - SBSR, 2011, INPE, Curitiba, PR, Brasil, p.15251531.

MMA - Ministério do Meio Ambiente dos Recursos Hídricos e da Amazônia Legal. Download de dados geográficos. 2004. Disponível em: <http://mapas.mma.gov.br/i3geo/datadownload.htm>. Acesso em Acesso em 27 de agosto de 2015.

NOVO, E.M.L.M. Ambientes Fluviais. In: FLORENZANO, T.G. (Org.). Geomorfologia: conceitos e tecnologias atuais. São Paulo: Oficina de Textos, 2008, p. 219-246.

SILVA, J.R.; MOURA, A.C.M. Delimitação automática de sub-bacias hidrográficas no município de Ouro Preto-MG. In: Anais do XVI Simpósio Brasileiro de Sensoriamento Remoto - SBSR, 13 a 18 de abril de 2013, INPE, Foz do Iguaçu, PR, Brasil.

SOARES, M.R.G.J.; SOUZA, J.L.M. Análise morfométrica da bacia hidrográfica do rio pequeno em São José dos Pinhais (PR). Revista: Geografia (Londrina). Londrina, v.21, n.1, p.19-36, 2012.

STRAHLER, A.N. Hypsometric analysis of erosional topography. Geological Society of America Bulletin, n. 63, p.111-1141, 1952.

TONELlO, K.C.; DIAS, H.C.T.; SOUZA, A.L.; ALVARES, C.A.; RIBEIRO, S.; LEITE, F. P. Morfometria da Bacia Hidrográfica da Cachoeira das Pombas, Guanhães - MG. Revista Árvore, v.30, n.5, p.849-857, 2006. 
USGS - United States Geological Service (Serviço Geológico dos Estados Unidos). Earth Explorer Digital Elevation - SRTM 1 Arc-Second Global. 2015. Disponível em $<$ http://earthexplorer.usgs.gov/>. Acesso em 23 de novembro de 2015.

Recebido em: 14/08/2016

Aceito para publicação em: 01/10/2016 